\title{
状態空間データベースを応用した移動システムの走行制御*
}

\author{
小河原 加久治*1, 中 務 大 視*2, 樋 口丈 浩*1
}

\section{Visual Feedback Vehicle Control Using State-space Database}

\author{
Kakuji OGAWARA*3, Hiromi NAKATSUKASA and Takehiro HIGUCHI \\ ${ }^{* 3}$ Factory Department of Mechanical Engineering, Yamaguchi University, \\ 2-16-1 Tokiwadai, Ube-shi, Yamaguchi, 755-8611 Japan
}

\begin{abstract}
Recent years, there are researches to operate vehicles by the voice instruction. It is important for these researches to recognize a peripheral environment. There are internal sensor and external sensor used to recognize a peripheral environment. Internal sensor is often used together with external sensor because the error with driving system is caused. Imaging sensor can especially measure the plane compared with other external sensors, the research combined with internal sensor is abundant. The delay is caused because it takes the processing time when imaging sensor is used. In this research, imaging sensor is installed on the vehicle, so the system is visual feedback control. State-space database is used to control the vehicle in this study. The vehicle can run on the straight corridor without the patterns like joint of the building. The vehicle cannot distinguish the patterns like joint of building on straight corridor and wall because same kind of feature appears to the objects. As result, the vehicle can be controlled regardless of the patterns like joint of the building on straight corridor. The state quantity of state-space database that solves this problem is found.
\end{abstract}

Key Words : Visual Feedback Control, Image Processing, Autonomy

\section{1. 緒言}

人間は視覚からの情報を使用して行動をしている. そのため, 視覚からの情報は非常に重要である.特に, 人間は自動車を操縦する際に道路に描かれた白線を利 用して，自動車が走行可能であるエリアを認識してい る.

移動システムにとって視覚のような情報はカメラ などの画像センサによって取得される，森ら ${ }^{(1)}$ は構内 道路において移動システムが走行可能である領域を画 像センサによって限定させ, 定形行動させている. 障 害物候補の領域があれば移動システムを停止させ， 2 台の画像センサによる三角測量を行って障害物を認識 させている. Ono ら ${ }^{(2)}$ は建物内の壁と廊下の境目を画 像センサから検出することで基本的な走行制御を行い， 赤外線センサで障害物を検出し, 周辺の環境の認識を 行った。 小畑ら ${ }^{(3)}$ はステレオ視を使用して対象物まで

\footnotetext{
* 原稿受付 2007 年 2 月 26 日.

*1 正員, 山口大学大学院理工学研究科 (画755-8611 宇部市常 盤台 2-16-1).

*2 山口大学大学院理工学研究科.

E-mail : ogawara@yamaguchi-u.ac.jp
}

の正確な位置を計測し，アームで対象物を回収した. 前山ら ${ }^{(4)}$ はカラ一画像を用いて歩道領域を抽出し, 歩 道沿いを走行させた.

以上の研究では，画像センサより距離計測や障害物 認識などたくさんの情報を引き出すことができるが, その全ての情報を得るためには処理に時間がかかる. そのため, リアルタイム性を要求する移動システムに は向いておらず, 移動システム周辺の情報を得るため だけの処理を行っている(5)(6)(7)(8)(9).

本研究では画像センサからより多くの情報を引き出 し，ビジュアルフィードバックの用途を広げることを 目的とする．このとき，建物内の廊下を移動するシス テムに搭載された画像センサの画像には, 通常左右の 壁と廊下の境目が直線で射影されていることから，そ の直線の状態量を画像センサから得ることで，廊下に 存在する移動システムの状態量を推定する.この状態 量の関係を状態空間データベースとして構成し，移動 システムの走行制御を行う.

\section{2. 移動システム}

図 1 に移動システムと画像センサより得られた画像 を示す．移動システムは電動車椅子に画像センサであ 
る供試カメラ, 計算機を搭載し構成されている. 画像 センサからの画像の大きさは 640(H) $\times 480(\mathrm{~V})[$ pixel], 1 画素あたりの濃淡レベル数が 8[bit]のモノクロ画像で ある. 図 1 に示すようにディジタル画像座標 $\mathbf{m}$ と移動 システム座標 $\mathbf{X}$ は斉次座標 $\widetilde{\mathbf{m}}, \widetilde{\mathbf{X}}$ より,

$$
\lambda \widetilde{\mathbf{m}}=\mathbf{A}[\mathbf{R} \mathbf{T}] \tilde{\mathbf{X}}
$$

の関倸がある，入は任意のスカラー，Aは内部行列， R は回転行列，Tは並進行列である. 式 (1) の移動シ ステム座標 $\mathbf{X}$ に対して，廊下上にあるという条件によ り, ディジタル画像座標 $\mathbf{m}$ から距離の測定を行うこと ができる.

図2 に画像処理のフローチャートを示寸，画像処理 はサンプリング時間毎に行う，画像センサから得た画 像は, コントラストを高くし, ノイズ除去とエッジ検 出を行い, 左右の壁と廊下のエッジを抽出する画像処 理を行う. 図3-A を原画像として図3-B は画像処理を した. 図3-B より左右の壁と廊下のエッジが検出され た. また, Hough 変換の処理コスト削減のため, 図3-B のようにエッジの探索範囲を限定している. 1 サンプ リング前のエッジの状態量から推定された範囲内で状
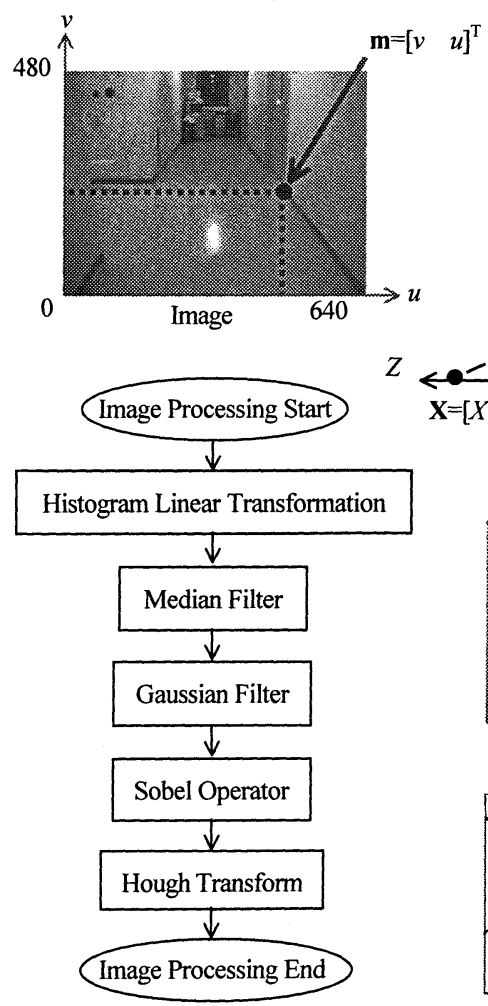

Fig.2 Flow chart of image processing
態空間データベースを検索する. そして, エッジが検 出される範囲を推定し,エッジの探索範囲を限定した.

\section{3. 状態究間データベース}

状態空間データベースの状態量を図 4 に示す. 廊下 に設置された移動システムの状態量 $\mathbf{E}$ は, d[\%]は廊下 の中央からの偏差, $w[\mathrm{~mm}]$ は廊下幅, $\psi[\mathrm{deg}]$ は廊下の 中央からの旋回量で構成されており，物理空間で定義 されている状態量である. 画像センサから得られる状 態量 $\mathbf{P}$ は左の壁と廊下のエッジの極座標 $\rho_{L}[\mathrm{pixel}] と \theta$ ${ }_{L}[\mathrm{deg}]$, 右の壁と廊下のエッジの極座標 $\rho_{\mathrm{R}}[\mathrm{pixel}]$ と $\theta$ ${ }_{\mathrm{R}}[\mathrm{deg}]$ で構成されており, 状態空間で定義されている 状態量である. これらの状態量 $\mathbf{E}$ と $\mathbf{P}$ の 7つの状態量 より, 状態量ベクトル $\mathbf{S}$ は構成される.この状態量べ クトル $\mathbf{S} を$ 予めデータベース化したものが状態空間デ ータベースである.

状態空間データベースを使用することで画像セン サの情報から移動システムが存在する廊下の環境を認 識する処理時間と画像センサから得る画像の処理時間 において高速化を行うことができる.

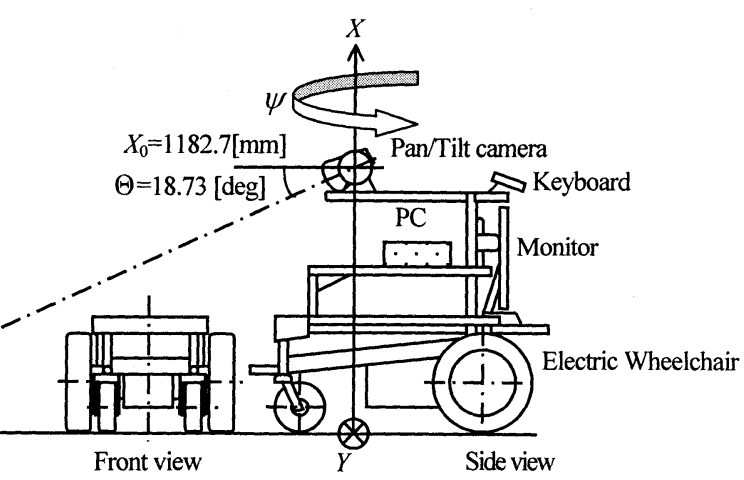

Fig. 1 The vehicle model

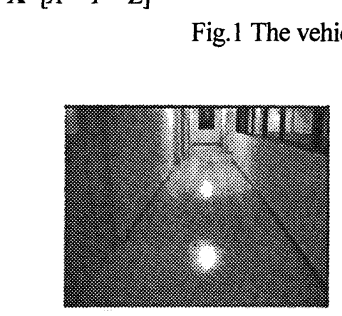

Fig.3-A Original image

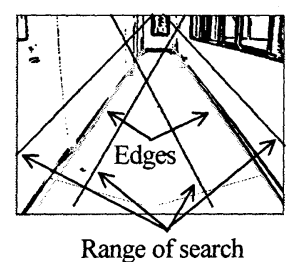

Fig.3-B Image processing

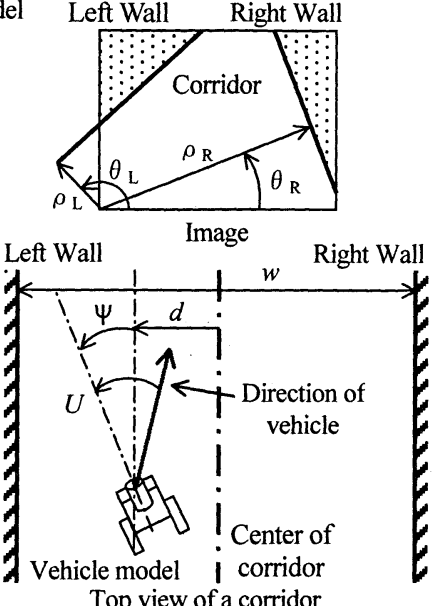

Fig.4 State variables of state-space database 


\section{4. 移動システムの走行制御}

移動システムの概要図を図 5 に示す. カメラ画像の エッジ抽出処理により得られた線分の角度を示す状態 量である $\mathbf{P}_{\mathbf{I}}$ と1サンプリング周期前の廊下の環境であ る $\widetilde{\mathbf{E}}_{\mathbf{B}}$ より移動システム周辺の廊下の環境を推定する. $\alpha$ を重み係数とした

$J(k)=\left|\mathbf{P}(k)-\mathbf{P}_{\mathbf{I}}\right|+\alpha\left|\widetilde{\mathbf{E}}(k)-\widetilde{\mathbf{E}}_{\mathbf{B}}\right|$

で定義された評価関数 $J(k)$ を考え, $k$ 行ある状態空間デ 一タベースから $J(k) を$ 最小にする $\mathbf{P}, \widetilde{\mathbf{E}}$ を探索し, 現 在の移動システムが存在する廊下の環境と推定した.

移動システムの進行方向は図 4 のように速度を一定と し，推定された現在の廊下に存在する移動システムの

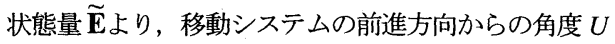
を

$U=K_{d} \tan ^{-1}\left(\frac{k_{d}\left(\tilde{d}-d^{\prime}\right) \times w}{1000}\right)+K_{\psi}\left(\tilde{\psi}-\psi^{\prime}\right)$

として走行方向を決定し制御を行った. $K_{d}, k_{d}, K \psi$ は 比例ゲインである. $\mathbf{E}^{\prime}=\left[d^{\prime} w^{\prime} \psi^{\prime}\right]$ は移動システムが走 行するときに目的とする廊下の環境である. 本研究で は移動システムを廊下の中央で走行制御させるので $d^{\prime}=0, \psi^{\prime}=0$ とした. 式（3）の第 1 項は廊下における 移動システムの位置の制御, 第 2 項は移動システムの 進行方向を廊下と平行にする制御である.

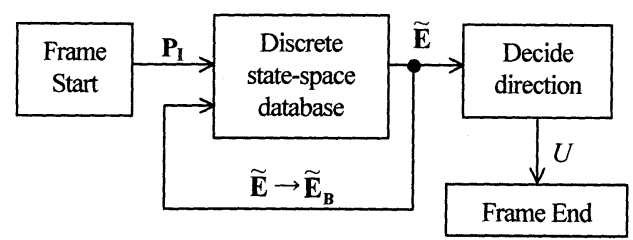

Fig.5 Conceptual diagram of using state-space database

\section{5. 状態空間データベースの応用}

図6はそれぞれ壁がある場合と建物の接合部が廊下 にある場合のカメラからの画像である. 図6をそれぞ れ比較したときは壁と廊下の区別ができる. 図7 は図 6 をそれぞれ画像処理した画像である. 図 7 をそれぞ れ比較したとき, 人間でも壁と廊下の違いを認識する ことが難しく,移動システムにとってはさらに難しい. これは同じようなエッジが存在し，廊下と壁の区別が できないからである.

この問題に対し, 図 7 のエッジ上を走行可能として, 移動システムの走行を予測する状態量 $\mathbf{P}_{\mathbf{N}}, \mathbf{E}_{\mathbf{N}}$ を定義
した. 図 8 は一般的な廊下の環境のモデルである. 現 在の状態量 $\mathbf{E}$, 移動システムから左右の壁までの距離 をそれぞれ $\mathrm{dL}, \mathrm{dR}$, 予測される状態量 $\mathbf{E}_{\mathrm{N}}$, 予想した 環境の移動システムから左右の壁までの距離をそれぞ れ $\mathrm{dL}_{\mathrm{N}}, \mathrm{dR}_{\mathrm{N}}$ とおく. 図8より壁と廊下の区別は

$$
\left|\theta_{L N}-\theta_{L}\right| \leq \varepsilon_{L}|\&| \theta_{R N}-\theta_{R} \mid \leq \varepsilon_{R}
$$

を満たす場合は廊下, 満たさなかった場合は壁とした。 $\varepsilon_{L}$ と $\varepsilon_{R}$ は状態空間データベースを利用して, 現在の 状態量 $\mathbf{E}$ と予測する状態量 $\mathbf{E}_{\mathbf{N}}$ が図 8 の条件を満たし たときに, 現在の状態量 $\mathbf{P}$ と予測する状態量 $\mathbf{P}_{\mathbf{N}}$ の差 により求めた.

一般的な廊下では図 8 のようにエッジを境目にして 廊下の環境が急激に変化するため, 予測する状態量 $\mathbf{E}_{\mathbf{N}}$ を使用して環境の変化に適応させた.

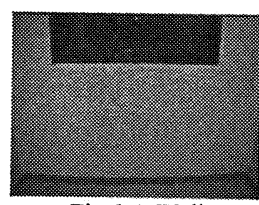

Fig.6-A Wall

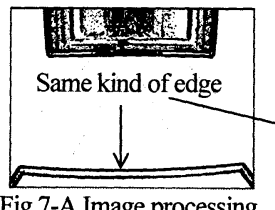

Fig.7-A Image processing (Wall)

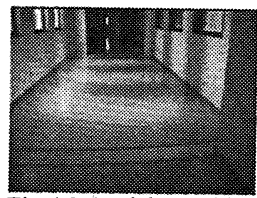

Fig.6-B Straight corridor

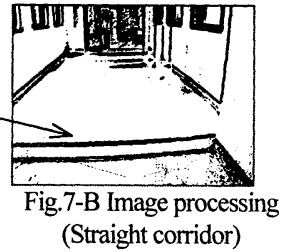

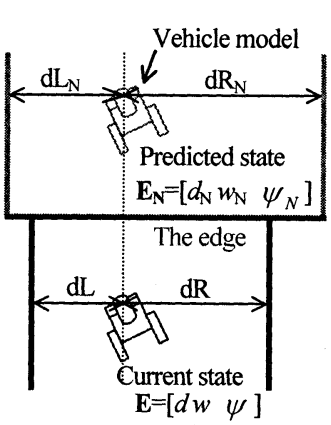

Top view of a corridor

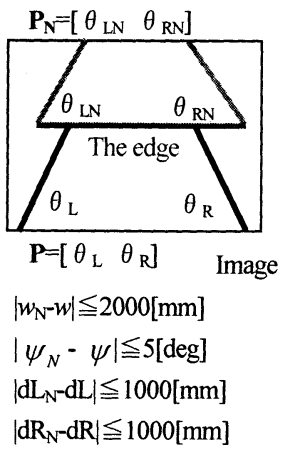

$\left|d R_{N}-d R\right| \leqq 1000[\mathrm{~mm}]$
Fig.8 Predicted state variables of state-space database 
状態空間データベースの範囲および刻み量を以下

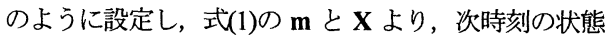
量E とPを推定して探索個数を限定することにより高 速化を図った.

$$
\begin{aligned}
& d=([-70,70]: 2 \%) \\
& w=([900,3500]: 10 \mathrm{~mm}) \\
& \psi=([-45,45]: 1[\mathrm{deg}])
\end{aligned}
$$

この探索手法はカオス非線型予測などで使われる 区分線形法 ${ }^{(10)}$ と同等の手法である. 状態空間データベ 一スを有限個のボックス(区分)に分け，実験で得られ た状態量の時系列データを, 予めオフライン処理で所 属するボックスに区分けして登録しておく.リアルタ イムで行う状態量予測の際には, 現在の状態量が属す るボックスを選択し, そのボックスに属する過去状態 量時系列データの中から一番近いモノを探索する. 供 試移動システムは，この過去状態量時系列と同様な時 間変化をすると仮定し，それを予測值として用いる. ボックス選択は状態量を整数化するなどしてボックス のインデックスとして用いることにより陽的に選択で きるため高速化が可能である．また，データベースを 構成する過去状態量デー夕数が一定であるなら，ボッ クス数を多くすると 1 つのボックス内の過去状態量デ 一夕数は減少し探索対象が減るため, 挆索速度の向上 が可能となる. しかし，ボックス数を多くして探索対 象を限定しすぎると，適切な過去状態量データが見つ かる確率も減るため, 隣接ボックスまで探索領域を広 げる必要が生じて探索時間が増加する. 本研究の場合, データベース構筑に用いる状態量データ数は, 移動シ ステムが走行する廊下の光環境によっても変化するが, 500 10000 個程度まで減らしても認識精度に悪影響は 現れないことが分かった。

\section{6. 実験と結果}

廊下幅が狭い環境から広い環境一走行させた場合 の実験場所を図9,壁へ向けて走行させた場合の実験 場所を図 10 に示す.

廊下幅が狭い環境から広い環境へ走行させた場合 で成功したときの移動システムの軌跡，画像センサの 画像, 画像処理した画像を図 11, 廊下に存在する移動 システムの状態量を図 12 に示す.移動システムの速度 は約 $0.36[\mathrm{~m} / \mathrm{s}]$, サンプリングタイムは $250[\mathrm{~ms}]$ とし, 廊下の中央で走行制御を行った. 図 11 の(1)から(5)は移 動システムの位置であり，そのときに画像センサに映
った画像が図 11-A から図 11-E である.図 11-B の点線 で囲まれた範囲は予測する状態量の探索範囲であり， 移動システムとエッジまでの距離によって経験的に決 定した.

図 11-Cのときに式（4）による廊下と壁の区別を行 い, 廊下と判断した。現在の状態量 $\mathbf{E}$ を予測する状態 量 $\mathbf{E}_{\mathbf{N}}$ に変化させ，エッジを境とした廊下の環境の急 激な変化に対応させた. 図 12 の 50 [frame]のときが図 11-C の状態である. 廊下の環境が変化しても廊下の中 央を走行している.

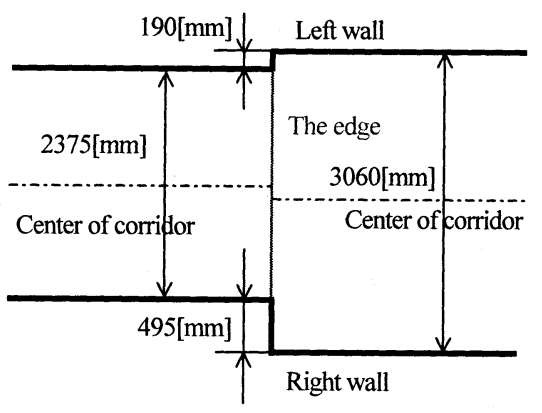

Fig.9 The top view of a straight corridor

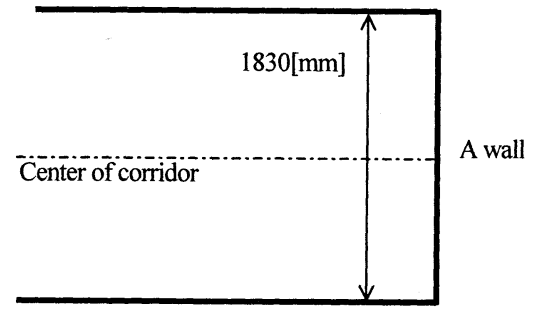

Fig.10 The top view of a wall

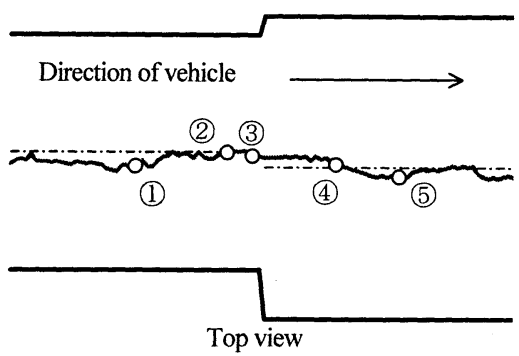

Fig.11 Result (a straight corridor) 


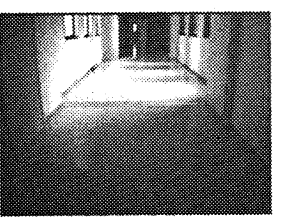

Original image (1)

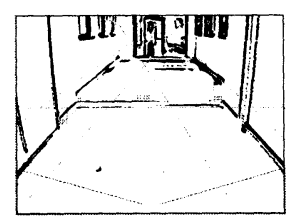

Image processing (1)

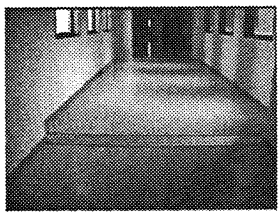

Original image (2)

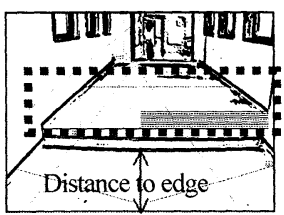

Image processing (2)
Fig.11-B State (2)

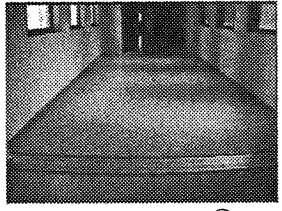

Original image (3)

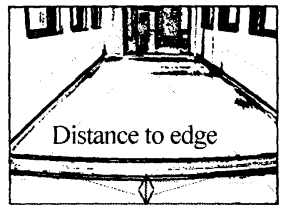

Image processing (3)

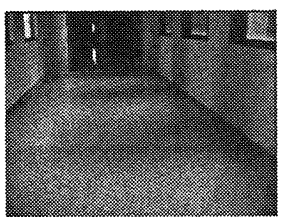

Original image (4)

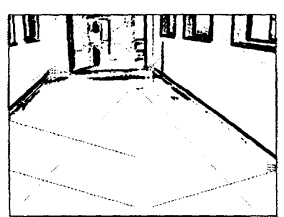

Image processing (4)
Fig.11-C State (4)

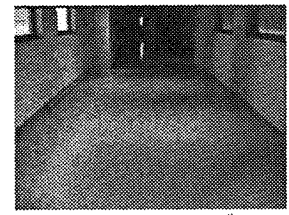

Original image (5)

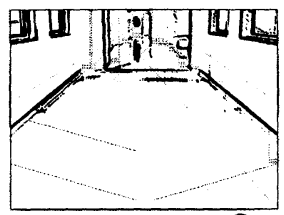

Image processing (5)
Fig.11-C State (5)

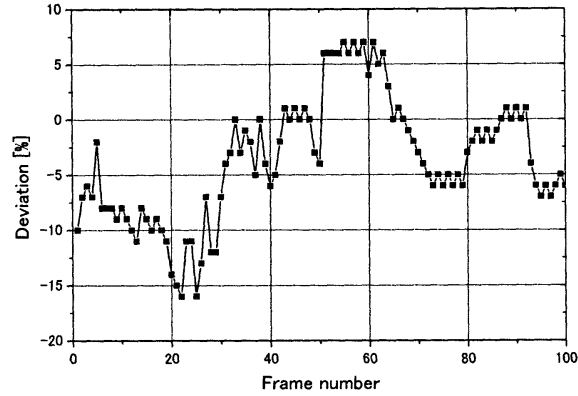

Fig.12-A Deviation $d$

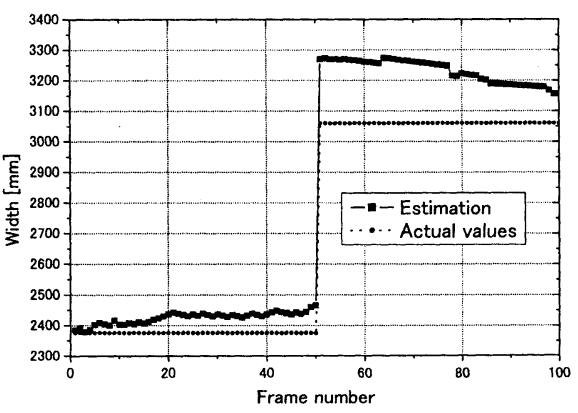

Fig.12-B Width $w$

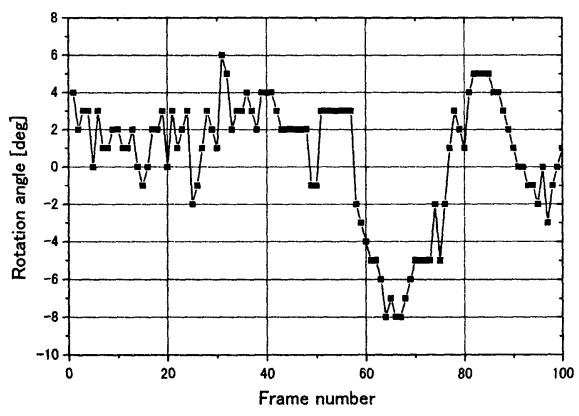

Fig.12-C Rotation angle $\psi$

壁の場合で成功したときの移動システムの軌跡，画 像センサの画像, 画像処理した画像を図 13, 廊下に存 在する移動システムの状態量を図 14 に示す.移動シス テムの速度は約 $0.36[\mathrm{~m} / \mathrm{s}]$, サンプリングタイムは 250[ms]とし，廊下の中央で走行制御を行った.

図 13 の(1)から(5)は移動システムの位置であり, そ のときに画像センサに映った画像が図 13-A から図 13-Eである. (4)と(5)は移動システムが停止している. 


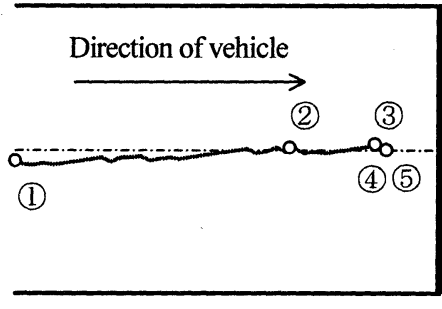

Top view

Fig.13 Result (a wall)

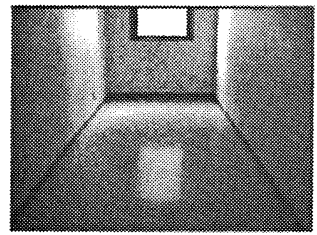

Original image (1)

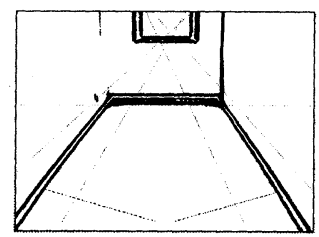

Image processing (1)
Fig.13-A State (1)

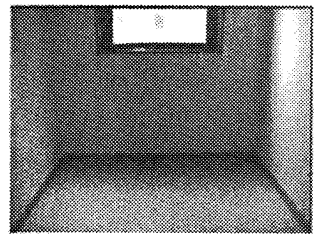

Original image (2)

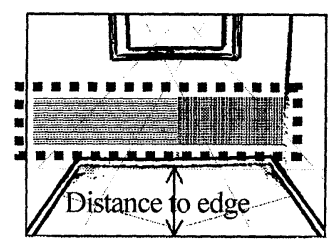

Image processing (2)

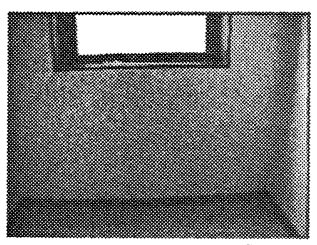

Original image (3)

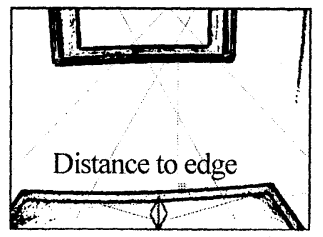

Image processing (3)

Fig.13-C State (3)

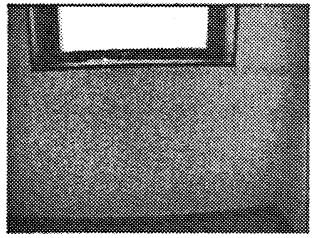

Original image (4)

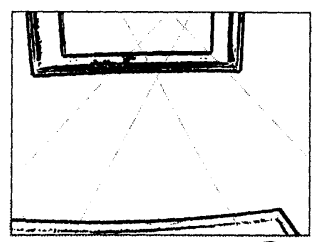

Image processing (4)
Fig.13-D State (4)

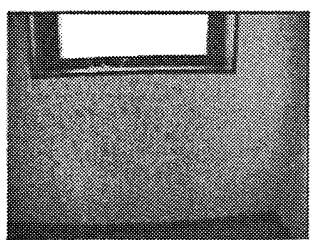

Original image (5)

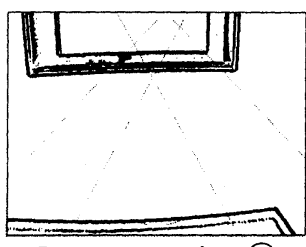

Image processing (5)
Fig.13-E State (5)

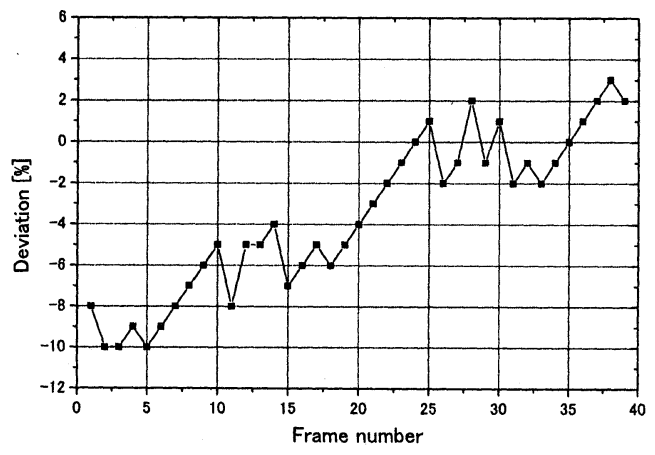

Fig.14-A Deviation $d$

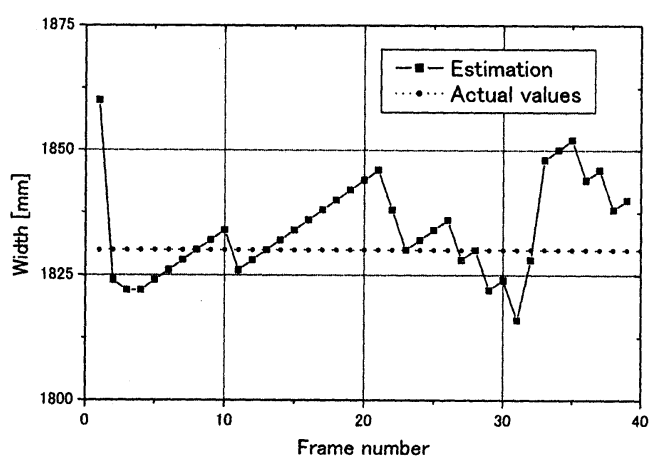

Fig.14-B Width $w$

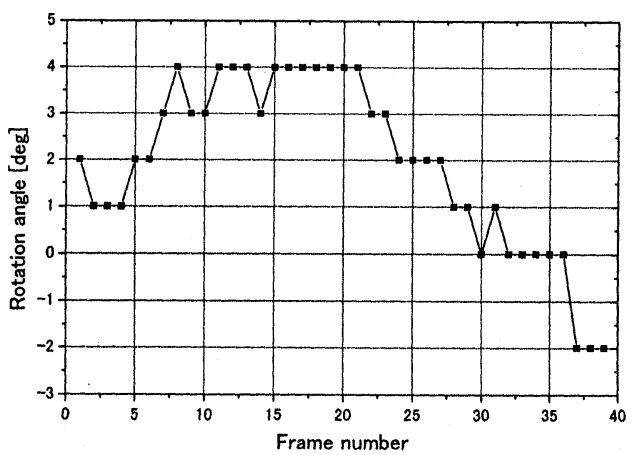

Fig.14-C Rotation angle $\psi$

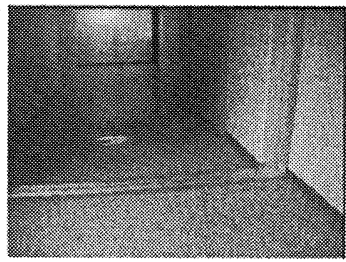

Original image

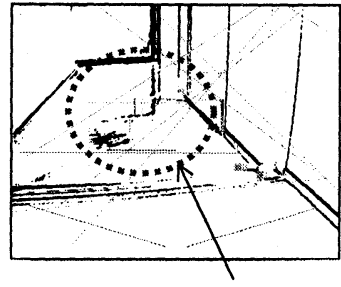

Unexpected edge

Image processing
Fig.15 Failure pattern 
図 13-C のときに式（4）による廊下と壁の区別を行 い, 壁と判断した. 壁へ向けて走行させた場合, 画像 の下の縁からエッジまでの距離により, 移動システム から壁までの距離を推定し, 衝突させないように停止 させる.

図 14 は移動システムの状態量であり, 廊下の中央 ·を走行している.

\section{7. 結言}

壁と廊下の区別は成功率 95.1[\%]であった. 壁へ向け て移動システムを走行制御した場合は壁を認識して停 止する成功率が 100[\%]であった.

一般的な廊下ではエッジを境目にして廊下の環境 が急激に変化することも珍しくない，廊下幅が狭い環 境から広い環境へ走行制御した場合は8 割以上の高い 成功率が得られ，本手法は有効であったと言える. し かし, 廊下幅が広い環境から狭い環境へ走行制御をし た場合には約 4 割の成功率であった.これは図 15 のよ うに天井の照明が廊下に反射して状態量空間が予測と 大きく違うためである. 本研究で用いたデータベース 探索の高速化が, 過去の状態から次を予測・推定するこ とにより探索領域を減らす手法であるため，本来の 廊下エッジの認識率が低下したものと考えられる. 画 像ノイズに対する頑強性を増すことが今後の課題であ る.

\section{文献}

(1) Mori, H. et al., Self-contained mobile robot in campus road, Journal of the Robotics Society of Japan, Vol. 5, No.5 (1987), pp. 361-374.

(2) Y. Ono, et al., A Mobile Robot for Corridor Navigation: A Multi-agent Approach, $A C M$ Southeast Regional Conference, (2004), pp. 379-384.

(3) Obata, M. et al., Development of Outdoor Service Robot to Collect Trash on Streets, Transactions of the Institute of Electrical Engineers of Japan, Series $C$, Vol. 126, No. 7 (2006), pp. 840-848.

(4) Maeyama, S. et al., Recognition of Walkway Area based on Color Image Segmentation and Autonomous Mobile Robot Walkway Following, Transactions of the Japan Society of Mechanical Engineers, Series C, Vol. 70, No.693 (2004), pp. 1380-1387.

(5) Ogawara, K. and Tanaka, M., Improvement of operativity Voice Controlled Vehicles by Visual Feedback Control, Transactions of the Japan Society of Mechanical Engineers, Series C, Vol. 70, No.689 (2004), pp. 158-163.

(6) Ogawara, K. et al., A Real-Time Image Recognition Method for Downward Stairways using Hough Transform, Transactions of the Japan Society of Mechanical Engineers, Series C, Vol. 70, No.695 (2004), pp. 1971-1976.
(7) G. Pires, and U. Nunes, A Wheelchair Steered through Voice Commands and Assisted by a Reactive Fuzzy-Logic Controller, Journal of Intelligent and Robotic System, 34(3), (2002), pp. 301-314.

(8) R. Simpson, et al., The Smart Wheelchair Component System, Journal of Rehabilitation Research \& Development, Vol. 41, No.3B (2004), pp. 429-442.

(9) T. Gomi, and A. Griffith, Developing Intelligent Wheelchairs for the Handicapped, In Lecture Notes in Artificial Intelligent, Vol. 1458: Assertive Technology and Artificial Intelligent, Springer-Verlag, (1998).

(10) K. Aihara, Analysis and Application of Chaotic Time Series, ISBN4-7828-1010-5, Sangyo Tosyo(2000). 